\title{
DAB: the future of radio? The development of digital radio in four European countries
}

\author{
Stephen Lax \\ UNIVERSITY OF LEEDS, UK \\ Marko Ala-Fossi \\ UNIVERSITY of TAMPERE, FINLAND \\ Per Jauert \\ University of Aarhus, DenMark \\ Helen Shaw \\ Dublin City University, IRELAND
}

Digital radio reached its tenth birthday in 2005. However, anniversary celebrations have been rather muted. In contrast with digital television, where audience awareness levels are high and adoption rates similar, digital radio's penetration into the marketplace has been minimal. Even when people have heard of digital radio, survey data shows that very few feel knowledgeable about it.

Nevertheless, most broadcasters and most governments believe that, just as most other consumer electronics is migrating from analogue to digital technology, radio too will eventually become all-digital. But development of digital radio is very variable, with some countries having a large number of digital radio services available across the whole nation, while others have very few services.

The picture is confused by there being a number of interpretations of the term 'digital radio'. Almost all households that receive digital TV, whether by satellite, cable or over-the-air terrestrial transmissions, will also receive a number of radio stations with that service. So listening to a radio station through the TV is one form of digital radio service. A second form is listening to streamed radio stations on the internet - this too can be regarded as

Media, Culture \& Society (c) 2008 SAGE Publications (Los Angeles, London, New Delhi and Singapore), Vol. 30(2): 151-166

[ISSN: 0163-4437 DOI: 10.1177/0163443707086858] 
digital radio. However, one of the key attributes of 'traditional' analogue radio is the ability to receive it in a number of locations, perhaps on a number of different portable radios located around one's house, or on a personal stereo (such as the 'Walkman') or in a car. None of the existing digital television systems allow for this portability or mobile reception; it is also currently not practicable to listen to web-streamed radio on portable devices. Instead, dedicated digital radio systems have been developed which replicate all the attributes of analogue radio in digital form, and the most advanced of these is the terrestrial DAB system (for Digital Audio Broadcasting), sometimes known as Eureka after the European Union (EU) research programme under which it was developed. The development of DAB began in 1987 with the involvement of broadcasters and equipment manufacturers from four countries, and domestic transmissions began in September 1995. Ten years later, 28 countries were operating DAB services, mostly in Europe but also including some advanced services in Canada, and trial services in Australia, China and South Africa (World DAB, 2005). Notable absentees from the list are the US and Japan, which have opted for different systems.

DAB was described from the outset as a potential replacement for analogue FM radio. Like FM it would offer high-quality sound (in comparison with AM), with a range of both national and local or regional stations. The advantages digitization would offer over and above FM included a greater number of stations, easier tuning of radio sets and the display of text services on the receiver display. The expectation was that, while DAB would remain essentially a technology for the delivery of radio services, the data carried on the $\mathrm{DAB}$ transmissions could also include multimedia information, and that the radio would become a more sophisticated device, capable of receiving graphical information and the ability to store and replay broadcast audio. The digitization of radio, then, presented a number of new possibilities for augmenting the service and even challenging the meaning of the term 'radio'.

However, these advantages have not proved compelling to listeners. Sales of $\mathrm{DAB}$ receivers have been slow. Although they are now cheaper than a few years ago, they continue to carry a premium in price over comparable analogue receivers, and thus listeners need a clear incentive in order to make the decision to purchase. This slow growth has also made some broadcasters and governments wary of investing in the DAB system. DAB requires the allocation of new frequency space and a reorganization of the broadcasting system, from one based on allocating particular frequency channels to individual stations, to one in which a wide frequency channel is allocated to a 'multiplex operator', which then carries a number of radio stations simultaneously on that channel. Thus there are legislative and regulatory processes involved. For the broadcaster, the introduction of DAB requires the conversion of its transmitter network to simulcast existing services, or the negotiation for the carriage of such services with the new multiplex operators. At the same time, the increased capacity of DAB implies that those same services will be competing 
with a host of new stations carried on the various multiplexes. Hence, depending on the particularities of the existing radio broadcasting landscape, from country to country there may be varying degrees of incentive for broadcasters and their governments to embrace DAB digital radio.

Thus, while some of the early visions for digital radio may have been cautious, even they appear now to have been over optimistic. Quentin Howard, head of the UK digital commercial operator Digital One, argued in 1999: 'All media is going digital.... To think that analogue radio will still be able to hold its own in ten years' time is unrealistic: it won't be able to compete' (quoted in Carter, 1999: 46). Now, well on the way towards that horizon, it seems clear that analogue radio is indeed holding its own and will continue to do so for many years to come. Few countries have discussed switching off analogue radio, and fewer still have actually specified a date for doing so. Once again, the contrast with television is striking, with several countries expecting to switch off analogue TV within the next decade. In attempting to explain the reasons for the relatively slow development of digital radio, the large degree of variation between different countries may well offer some clues.

The level of development of DAB services varies greatly: from none at all to relatively advanced. While, as we have noted, there are some developments outside Europe, in some cases based on quite different technical standards, it is in Europe where the most developed services are to be found. The DAB project began in Europe, and it is most advanced in northern Europe where the project's member countries are principally located. The level of DAB service can be judged on three criteria: the geographical coverage of DAB signals; the number of stations available on DAB; and the number of receivers in use. On this basis, some countries can be considered to have well-developed services: for example with wide geographic coverage, public and some commercial stations on digital, and a significant adoption of receivers by the public. Others might have a medium level of development, with some services operating but far from national geographical coverage and a consequent low take-up of receivers. Low levels of development exist in other countries with often only trial DAB services and almost no public adoption of receivers. Some examples are listed in Table 1.

Necessarily, the picture illustrated in Table 1 represents a snapshot. Particularly in the early days of its introduction, the level of service in any particular country can change rapidly and so recording the state of development at a particular time gives only a partial understanding of DAB's status. Instead, a fuller understanding is obtained by looking at the development over time of DAB in different countries and identifying the different factors which have influenced that development.

We examine here the long-term development of DAB in four countries from Table 1: the United Kingdom, Denmark, Finland and Ireland. These countries straddle the full range of levels of DAB's development across Europe and allow us to examine the role of governments, broadcasters and the 
TABLE 1

DAB after 10 years: levels of development of selected European countries in late 2005

\begin{abstract}
High levels of $D A B$ services
Belgium $98 \%$ of population is covered. Public radio stations on DAB, including some digital-only. Low but increasing sales of receivers.

Germany $\quad 85 \%$ coverage. Around 80 stations, public and commercial, but relatively low rates of receiver ownership.

United Kingdom $85 \%$ coverage. Large no. of stations on DAB, public and commercial (some digital-only). Approx. 3m receivers.

Medium to high levels of service

Denmark $\quad 90 \%$ coverage. Public stations on DAB and one commercial station, but little interest from commercial radio. Steadily increasing numbers of receivers.

Norway $\quad 70 \%$ coverage. Mostly public stations (some digital-only), and two commercial simulcasts. Low penetration of receivers.
\end{abstract}

Low to medium levels of service

Finland $\quad 40 \%$ coverage but transmission ended in 2005. Public stations only (some digital only) until cessation. Low penetration of receivers.

Netherlands $\quad 70 \%$ coverage. Public stations mostly, some commercial licences expected to be granted in 2006.

Sweden $\quad 35 \%$ coverage. Public stations only, service curtailed in 2002 due to low receiver penetration. Government support for expansion of DAB withdrawn in 2006.

Low levels of service

France

Services exist in a small number of cities on the L-band only.

Earlier services elsewhere have now ceased, while Band III

trials continue in Paris. Low penetration of receivers.

Hungary Two transmitters cover parts of Budapest only. Public stations

Ireland only, one digital-only. Almost no receivers owned by public.

No DAB transmissions other than some re-launched trials in Dublin.

Source: Data extracted from CEPT (2005).

audience in shaping the development of digital radio. The UK is recognized as the leading country in Europe (and indeed in the world) in terms of the number of stations broadcast on DAB, both public and commercial, and in terms of the number of receivers in households. Denmark is also relatively advanced in having all public stations on DAB including some new digitalonly stations, although commercial radio has only recently begun DAB transmissions. Here, while the number of receivers has been relatively low, in 2005 and 2006 the rate of adoption has increased towards UK levels. Finland has operated a DAB service for some years, like Denmark carrying only the public broadcaster's stations. However, take-up of receivers by the public has remained low and the public broadcaster switched off its transmissions in 
August 2005, with fewer than 1000 receivers sold by 2004 (YLE, 2004). Ireland never began a domestic service after initial trials, and not surprisingly almost no receivers have been bought by the public (those that have are used near the border with Northern Ireland, where there is a UK-operated service). The different approaches in these four countries demonstrate the complexity of the processes involved in introducing a new digital technological system into broadcasting, and the limitations of an approach based largely on technical assumptions adopted in the initial stages of DAB's development.

\section{DAB - four brief histories}

The Eureka 147 project under which DAB developed reached fruition in the mid-1990s when a number of European countries began trial broadcasts, with full domestic services beginning soon after. Public service broadcasters were the first to offer digital services: in the UK the BBC transmitted its five existing stations in digital format from 1995, while YLE in Finland initially began digital-only services from 1998. In Denmark, DR began full domestic DAB services in 2002. In those early days, coverage levels were low, typically reaching around 40 percent of each country's population, but in the UK and Denmark coverage grew steadily as more transmitters were built (or existing ones converted), and in both countries 85 percent or more of the population can receive DAB signals. Finland's network has not expanded significantly, with coverage limited at 40 percent. As we have noted, in Ireland, no domestic DAB service emerged after the initial trials, which ceased in 1999, although RTÉ recommenced further, Dublin-based trials in 2006.

Frequencies for DAB were allocated to each country at the Wiesbaden World Radio Conference in 1995. Each frequency block carries a single DAB multiplex, and each multiplex can be coded to transmit typically between 5 and 10 radio stations. A multiplex can be relayed on a 'single frequency network' to provide national services to a whole country, or used on a regional and local basis, and most countries operate both national and local multiplexes in a manner similar to the allocation of analogue FM frequencies. Digital transmission differs from analogue though, in that allocating a DAB multiplex to a particular area in effect creates capacity for around 10 radio services in that locality. For national networks, this is not a particular problem. Public broadcasters in most cases already operated a suite of national stations: the BBC, YLE and DR were able simply to simulcast existing stations on a national DAB multiplex, with the option of adding new, digitalonly services later. For local services, however, the capacity of the new DAB multiplex would often exceed the number of existing local radio stations operating in that area. Thus the introduction of a DAB multiplex structure created a potential dramatic increase in capacity for radio stations, both local and national. At least one commentator suggested, perhaps over-flamboyantly, 
that the introduction of digital transmission would 'probably mark the first time in broadcasting that there will be more channels available than content to fill them' (Crisell, 2002: 279).

In all four countries considered here, radio is strongly regulated with established public service policies, and it is to be expected that policy for digital radio would see a leading role for each country's respective public broadcaster. The expectation was that the public broadcasters would build the first networks, simulcasting their existing suites of stations, and that in time commercial radio companies would follow this lead. The steps taken to encourage commercial radio to invest in digital radio reveal a marked difference in policy decisions taken by the different countries. In the UK, while one national multiplex was operated by the BBC, the additional national multiplex and all the local or regional multiplexes were to be operated by commercial companies, which would in turn contract with commercial radio companies in order to carry their stations, whether national or local. In most cases, the fees charged to those stations for digital transmission were higher than the costs of analogue transmission, and so represented a significant cost. However, under the provisions of the 1996 Broadcasting Act, any existing analogue commercial radio station which began digital transmissions would be granted automatic renewal of its analogue broadcasting licence, a valuable commercial asset and thus a significant incentive to invest in DAB.

Elsewhere, in both Finland and Denmark, no equivalent incentive was offered to commercial radio, but instead a condition of the national stations' analogue licences was a requirement to begin digital transmissions at some later date (local commercial stations were not expected to join DAB at this stage). Here the plan was to use the public service broadcasters as the DAB locomotive. DR and YLE were charged with developing and operating the DAB networks in order to develop the market. Once established or at least demonstrated, with sufficient numbers of receivers sold, the expectation was that commercial radio would willingly join in DAB's further development. In Ireland, where there remains unused capacity within the analogue FM spectrum, commercial radio companies showed no interest in digital radio and thus the public broadcaster, RTÉ, was responsible for initial trial transmissions but also saw little reason to continue after that.

The expectation that, other than in Ireland, commercial radio would enthusiastically embrace DAB, has not proved to be the case. In Finland, on renewing its analogue licence in 2001, the national commercial station, Radio Nova, successfully negotiated away its obligation to transmit on digital. In Denmark, the two national commercial stations only began simulcasting in August 2005, though rather reluctantly, both companies expecting to lose money on their digital services. In fact, three months later one of the stations, Sky Radio, ended all broadcasts - analogue and digital - for financial reasons, the costs of $\mathrm{DAB}$ transmissions being only one, relatively minor factor. In the $\mathrm{UK}$, while commercial radio does have a significant presence on DAB, 
nevertheless more than half have not begun digital transmission, principally on economic grounds: the cost is simply too high. In many cases these are the smaller stations, which are not part of the large radio groups, and which are therefore less able to afford the investment.

The presence or absence of commercial radio on the DAB multiplexes, on the basis of these four cases, would appear to be an indicator of the general health of DAB in these countries. The UK in particular, and more recently Denmark, has a level of involvement from commercial radio, backing up the initial efforts of its public service broadcasters. In comparison with other countries, comparatively high numbers of receivers have been sold (see Table 1) although these sales figures represent only a relatively small percentage of households. In Finland, however, commercial stations have not begun DAB transmissions and, correspondingly, public broadcaster YLE clearly sees little future in the technology, having already switched off its DAB transmissions. In Ireland, as we have noted, neither public nor private broadcasters made it to air.

Hence we see in these four countries considerable variation in the implementation of a digital successor to analogue FM radio. With broad similarities in their broadcasting histories, this might have suggested that digital radio would also develop in similar ways, but this has clearly not been the case. We focus next on the differences between policies adopted by the government in each country and seek to explain these variations by examining the existing radio 'landscapes' which these policy decisions reflected.

\section{Radio landscape and factors in the development of DAB}

Radio in each of the countries studied here follows what might be termed a classic Northern European model: a strong public service broadcaster maintained a monopoly of radio broadcasting long after public service television was joined by commercial competition. In radio, the first commercial stations were local, with national or regional coverage the domain of the public service stations (though public service local radio stations already existed in the $\mathrm{UK}$, provided by the $\mathrm{BBC}$ ). In the UK, licensing of local commercial stations began in the 1970s, but accelerated after the 1990 Broadcasting Act which allowed for the rapid expansion in the number of local commercial services, the launch of three national commercial services and a number of regional commercial stations. A similar pattern developed in Finland, where initial local commercial stations have been joined more recently by regional and national stations; in Denmark and Ireland, a third sector of much smaller community stations developed in addition to local and regional commercial services, with one or two national commercial stations beginning in more recent years.

There have been significant differences in the rates of progress, however, reflecting the sometimes precarious economic state of commercial radio. For 
example, Ireland's first national commercial station was launched in 1992, but failed early on and a more careful management of licensed spectrum meant that it wasn't for another five years that a second attempt was made to provide national commercial radio, this time successfully, with Today FM remaining the only national commercial station in that country. In Denmark, it wasn't until 2003 that a national commercial station was licensed. The rapid growth of commercial radio in the UK during the 1990s almost exhausted the supply of FM frequencies and here, unlike other countries, the less valuable AM band (medium wave) remains extensively used for local and national commercial broadcasting. In Denmark too, expansion of commercial radio has left limited scope for expansion, and the commercial radio companies are arguing for spectrum reconfiguration to release further capacity. Finland also has only limited capacity remaining within the FM spectrum, but in Ireland the management of the spectrum has left a number of unused frequencies, and the regulator, the Broadcast Commission of Ireland, announced a further programme of licences to be awarded from 2005.

So we can begin to explain the different approaches adopted by each country's government: while there are certainly similarities between these countries' radio landscapes, there are also differences (Table 2). These include: the availability of spare FM spectrum; the relationship between commercial and public service radio; the balance between local and national services. These differences have all shaped the development of the DAB policy (and thus the current level of its development) in each country.

As the most advanced DAB country, the UK offers the clearest example of this shaping in its enticement of commercial radio. For, despite its rapid expansion resulting in a large number of stations, commercial radio's success there has been qualified. Taken as a whole, its share of the audience continues to struggle to match the BBC's, only once gaining more than 50 percent, and declining slowly since to a low of 43 percent at the end of 2005 (Rajar, 2006). While its share of national advertising revenue grew during the 1990s when the number of stations was expanding, it has been either stable or in slight decline since (RAB, 2006). With the limited availability of new FM spectrum, commercial radio could only anticipate further incremental growth in analogue radio, but early decisions on digital radio policy enshrined in the 1996 Broadcasting Act made it clear that here commercial radio was to have a leading role. With the awarding of the multiplex operating licences to the existing large commercial radio groups (four groups hold all the licences between them, with additional smaller partners in some instances) $)^{1}$ this represented a significant shift in weight from the BBC towards commercial radio, particularly at the national level where there would now be as many commercial as public service stations. While the additional capacity offered by DAB (approximately twice as many stations in any particular area than on analogue) would allow further expansion, the control of the multiplexes by the existing large radio groups coupled, as we 
TABLE 2

The analogue radio landscape in Denmark, Finland, Ireland and UK

\begin{tabular}{lcccc}
\hline & Denmark & Finland & Ireland & UK \\
\hline Geography: & & & & \\
$\quad$ Population (millions) & 5.4 & 5.2 & 4.1 & 60.1 \\
$\quad$ Area (km²) & 43,094 & 338,145 & 70,273 & 244,101 \\
Radio began: & & & & \\
$\quad$ National & 1925 & YLE 1926 & RTÉ 1926 & BBC 1922 \\
Local/regional & 1983 & 1976 & 1988 & 1967 \\
Community & 1983 & 1987 & 1988 & 2002 \\
Commercial/private & 1988 & 1985 & 1988 & 1973 \\
National commercial & 2003 & 1997 & 1992 & 1992 \\
No. of stations: & & & & \\
National public & 4 & 3 & 4 & 5 \\
Local/regional public & 9 & 28 & 0 & 40 \\
National commercial & $2 *$ & 1 & 1 & 3 \\
Local/regional commercial & 123 & 78 & 27 & 282 \\
Local non-commercial/community & 165 & 4 & 26 & 107 \\
Advertising revenue: & & & & \\
Radio's total ad revenue (€ million) & 31.4 & 48 & 97 & 867.4 \\
Radio's share of all advertising (\%) & 2.4 & 4.2 & 9.0 & 4.5 \\
Average daily listening (minutes): & 225 & 202 & 244 & 206 \\
Share of listening: & & & & \\
All public stations & 70 & 50 & 43 & 55 \\
All commercial stations & 30 & 50 & 57 & 43 \\
Daily reach: & & & & \\
All radio stations & 84 & 80 & 87 & $90^{\dagger}$ \\
All public stations & 32 & 52 & 54 & $66^{\dagger}$ \\
All commercial stations & & & & \\
\hline Not & & 55 &
\end{tabular}

Notes

* One station ended broadcasting in 2005 but was replaced in early 2007.

${ }^{\dagger}$ UK figures are for weekly reach.

shall see, with a relaxed regulatory regime, would help to give these groups a competitive advantage. The inclusion of a further particular incentive, the automatic renewal of existing analogue licences, finally persuaded commercial radio companies to risk the investment in DAB.

The contrast between the UK and Ireland is striking. In Ireland the government avoided supporting any particular technical platform for digital radio and, following a report by consultants Deloitte \& Touche in 2001, adopted a twoyear 'wait and see' policy, awaiting evidence from other countries of the success (or otherwise) of DAB. This, again, can be explained by reference to the pre-existing state of analogue radio. Commercial radio here is mostly local (there is just one national commercial station), and in some cases very local. 
Meanwhile, the public broadcaster RTÉ has no local stations. Local radio has an unusually strong position in this country, with some of the highest listening figures in Europe, and collectively has a powerful lobbying voice. There is also a healthy community radio sector. As noted earlier, the capacity exists within FM for further growth at both national and local level, though the experience of earlier failures in national commercial radio has resulted in caution on the part of the regulator in releasing spectrum and meant only measured demand for expansion from the radio industry. Thus the additional capacity offered by DAB was not a clear-cut benefit, and it was treated warily or even with hostility by the commercial radio stations. RTÉ itself was somewhat equivocal in its approach, and thus the government was under no particular pressure, economic or political, to accelerate the development of DAB. The local nature of many of Ireland's commercial stations and the relative strength of the community radio sector compounded the difficulties with the adoption of DAB - DAB technology is rather inflexible in comparison with analogue FM in its geographic coverage; while highly spectrum efficient for national coverage, DAB becomes far less efficient for smaller coverage areas. An indication of this indifference to $\mathrm{DAB}$ was given by the organization representing Ireland's community stations, which argued that 'DAB is not a pressing issue for us at the moment', suggesting instead that progress in the UK be monitored (CRAOL, 2004). The government position has remained cautious: a second consultants' report in 2004 urged the establishment of a policy unit for digital platforms, but highlighted difficulties with $\mathrm{DAB}$ and suggested that 'the business case for DAB is as yet unproven' (OX Consultants, 2004: 20). This was reinforced later that year by a recommendation from the communications regulatory body, ComReg, that the spectrum allocated to DAB should be used in fact for a terrestrial digital television system, DVB - which can, of course, also deliver radio stations alongside its digital TV channels (ComReg, 2004). Only with the potential reallocation of unused frequencies at the ITU's 2006 Regional Radio Conference (RRC06) has interest sharpened in advancing digital broadcasting in Ireland (RTÉ, 2005: 14).

In Denmark and Finland, the FM spectrum also has limited capacity for further expansion. In Denmark, commercial radio, which operates predominantly in local coverage areas, was effectively ruled out of DAB's early development, as the platform's variable efficiency in its use of frequency encourages multiplexes to be arranged to cover either the whole country or at least large regions. The DAB multiplexes are thus populated entirely by existing and new public service stations from DR, with the exception of provision for the two national commercial stations, Sky Radio and Radio 100FM. Other commercial stations, covering small geographical areas, will not find space on the DAB platform until the introduction of new L-band frequencies towards the end of the decade. ${ }^{2}$ With commercial radio's audience share at around 30 percent, and the 2005 demise of Sky Radio, DR remains the driver for DAB in line with Danish digital broadcasting policy. The DAB structure in Finland posed similar difficulties for local commercial stations: the 
geographical coverage areas of the DAB multiplexes were regional in nature rather than local, vastly exceeding the existing reach of local stations. As early as 1995, the Finnish Ministry of Transport and Communications stated that 'either the Finnish commercial local radio stations must be turned into regional stations with significantly larger coverage areas, or they need another, alternative frequency allocation' (MINTC, 1995: 24). As in Denmark, local stations in Finland would have to wait for L-band frequencies to become viable in future years. With the two largest commercial radio companies withdrawing plans for DAB (one, SBS, choosing instead to invest in digital TV), it was again left to public broadcaster YLE to develop the DAB networks, carrying its national and regional stations (Ala-Fossi, 2001: 12).

This mismatch between DAB's 'local' coverage and existing local analogue stations clearly makes DAB unattractive to these countries' commercial radio stations. Even in the UK, where an allocation of five multiplex frequencies for local services in addition to the two national frequencies allows greater flexibility in planning coverage than in the other countries (where each had a total allocation of two frequencies) the geographical reach of DAB transmissions has tended to match the bigger 'local' or regional stations, leaving out both the smaller commercial and the new community stations. Augmenting this more suitable multiplex geography, the UK had additional policy strategies to encourage commercial radio to become a major part of DAB from the outset. In addition to straightforward commercial incentives (awarding of multiplex licences on a commercial basis; automatic renewal of analogue radio licences) the digital radio regulator, the Radio Authority, was to take a 'lighter touch' to regulation in comparison with its role in analogue radio. For example, decisions about which stations should be carried on a particular multiplex were largely to be determined by the commercial multiplex operators, and such decisions were to be made on a commercial basis (with the sole exception of the obligation to carry the local BBC station if it covered the same locality). The regulator was unable to intervene in such decisions:

...the Authority is not empowered to specify the types or numbers of digital sound programme or additional services which it expects to be provided on a multiplex....[D]ecisions about the choice and nature of sound programme and additional service providers are for the multiplex licence applicant to make. (Radio Authority, 2001: 21)

When the new regulator, the Office of Communications (Ofcom) took over the Radio Authority's role in 2003, it too argued that there was less need to regulate commercial radio in the digital sector:

'The general principle ... is that as spectrum constraints lessen, the need for regulation decreases, as the market provides ever wider choice. It could be argued that, as digital take-up grows, the need for regulation on analogue platforms will decrease, as listeners can experience the wider choice available on all platforms. (Ofcom, 2004: 57) 
The lack of regulation on the composition of the digital radio multiplexes has allowed the large commercial radio groups which own the multiplex licences to increase networking between stations and to turn local analogue stations into 'quasi-national' stations on digital radio. Thus stations with analogue transmissions only in London, for example, can be heard across the country on DAB multiplexes, becoming more valuable to their owners in attracting advertising revenue. Similarly, new digital-only stations launched by the radio groups are carried on most of those same groups' multiplexes in different parts of the country. While this makes obvious commercial sense, it compounds the exclusion from DAB of smaller commercial and community stations, already facing problems with multiplex coverage areas, and this segregation has been the subject of a report commissioned by the Digital Radio Development Bureau, which recommended that frequencies for still more Band III multiplexes be found or that, as in Denmark and Finland, L-band provision be explored. However, neither recommendation is a proven solution, and the report recommended further investigation (Smith, 2005). Hence, for local and community radio stations, $\mathrm{DAB}$ presents some difficulties rather than opportunities.

\section{Conclusions}

The four countries examined in this study reveal quite different approaches to the launch of digital radio. Ten years ago, each was beginning from more or less the same position: the DAB system was proven technically but not commercially and was to be introduced into an uncertain market. A decade later, four different outcomes have been reached, with one country leading by far while another remains at the starting gate (the other two being somewhere in between but moving in divergent directions in recent years). The differences result from the varied policy decisions taken by the governments and broadcasters in those countries, policies that both reflected and also reinforced differences in the existing organization and structures of radio in each country, but which were also constrained by the technical limitations of the DAB system. The UK government has been most explicit in its policy on digital radio. In order to secure the growth of digital radio, it has been organized in such a way that commercial radio companies would be encouraged to participate, a position in evidence also in the organization of digital television (Galperin, 2004). In particular, the size of the commercial radio industry and its relatively high concentration of station ownership has meant that, as UK DAB policy evolved, the larger commercial radio companies have been able to expand and strengthen their position in relation to the $\mathrm{BBC}$ in a deregulating environment (Lax, 2007).

In contrast, development of DAB in Denmark has been driven by the public service broadcaster DR, with little support from commercial radio. While DR maintains a substantial share of analogue listening - the highest 
of the four countries considered here - the arrival of local commercial radio, and still more recently of national commercial radio competing directly with its own national and regional stations, has forced DR to respond and introduce radical changes (Jauert, 2003). It has expanded substantially its provision on $\mathrm{DAB}$ and other digital platforms such as internet radio since the relatively late launch in 2002 . Here, the relative indifference of commercial radio to DAB has not inhibited growth; instead, it is this augmentation of an already popular public broadcaster's output that appears to have steadily driven recent sales of receivers to the point where approximately one in ten households have a DAB receiver, a proportion similar to that in the UK.

In Finland, with a similar radio landscape to Denmark, digital radio has largely been underpinned by a policy commitment to increasing the availability and take-up of digital TV, which of course can also deliver digital radio stations. While public broadcaster YLE did begin transmitting services on DAB from 1998, at the same time a report for the Finnish Agency for Technology and Innovation emphasized the importance of digital TV for the delivery of multimedia services, and by 2001 YLE had decided against further expansion of the DAB network (Autio, 2001; Guy and Stroyan, 1998). As we have noted, commercial radio did not invest in DAB. In 2003 the first commercial digital radio licences were awarded instead for delivery over the digital terrestrial television (DVB-T) platform rather than DAB, and now the full range of public service, commercial and digital-only services are available on this system. In 2004, the Finnish government's communications ministry concluded that, 'at this stage there are no particular reasons to hasten the digitalization of radio' (MINTC, 2004: 12). In addition, Nokia, Finland's largest company and a world leader in telecommunications, had already taken an early decision, in 1997, to withdraw from development of DAB devices in favour of concentrating on the DVB-T television platform, with its greater potential for multimedia services. Its subsequent development of a mobile version of DVB-T, DVB-H (digital video broadcasting, handheld) for delivery of multimedia (including radio) has reinforced YLE's 2005 decision to end its DAB transmissions, effectively signalling the end of DAB in Finland, with the regulator also indicating tacit support for the DVB-H alternative (Ficora, 2004; MINTC, 2003).

The lack of development of DAB in Ireland perhaps most clearly demonstrates the combination of factors influencing digital radio policy. With FM spectrum still available, and no interest from commercial radio in DAB because of its unsuitability for local broadcasting, the incentive for the development of DAB was more a rather abstract case of not being 'left behind' in the technological onward march rather than a clear economic argument for DAB's potential for expansion. The advice received in government consultations was generally cautious, with some conflicting recommendations: initially, to wait and observe how DAB fared elsewhere; later for either a steady roll-out of DAB or, 
conversely, for the use of the spectrum for digital TV. It is perhaps not surprising that in these circumstances, with the substantial costs of developing DAB not seen by the industry as justified, that government policy remained reticent.

We have presented here an account of a situation still under development. While the radio industry is continually changing in each of these four countries, the technological possibilities are changing faster still during the course of this research, a number of new digital radio platforms have been considered around the world. However, the experiences of the introduction of the 'original' and certainly most long-lived platform highlight some of the complexities of the paths along which new platforms must evolve.

\section{Notes}

1. One of the four groups was actually two separate companies when the licences were awarded. GWR and Capital Radio merged in 2005 to become GCap Media, which consequently owned the largest single share of the 47 commercial multiplex licences.

2. In the higher-frequency L-band, DAB can in principle operate over smaller coverage areas, although inefficiently. However, the L-band has hitherto not been used extensively for broadcasting and so it is unclear how appropriate it may prove to be in this role.

\section{References}

Ala-Fossi, M. (2001) 'From Channel Competition to Cluster Competition: Finnish and American Radio Formatting 1985-2000', presented at the 46th Annual Convention of the Broadcast Education Association, Las Vegas, 20-23 April.

Autio, M. (2001) 'Digiradio soi toistaiseksi harakoille' [For the Time Being, Digital Radio Broadcasts for Nobody], Helsingin Sanomat 11 November.

Carter, M. (1999) 'The Changing Face of Radio', Director March: 42-6.

CEPT (European Conference of Postal and Telecommunications) (2005) 'Status of the Implementation of T-DAB in the CEPT Area', document no. WG RRC06(05)021, CEPT, February, URL (consulted May 2005): www.ero.dk

ComReg (2004) ComReg Response to Consultation on Frequency Spectrum Policy for Digital Broadcasting, Document 04/93. Dublin: Commission for Communications Regulation.

CRAOL (2004) Response to the Review of Radio Licensing Report. Dublin: CRAOL.

Crisell, A. (2002) An Introductory History of British Broadcasting, 2nd edn. London: Routledge.

Ficora (2004) Tukholman tv-taajuussopimuksen uudistamista valmistelevan työryhmän (ST61REV) 3. kokous, kokousmuistio ST61REV 02(04) [Minutes of the Third Meeting of a Preparatory Working Group for the Renewal of the Stockholm Television Frequency Agreement. ST61REV 02(04)]. Helsinki: Finnish Communications Regulatory Authority.

Galperin, H. (2004) New Television, Old Politics: The Transition to Digital TV in the United States and Britain. Cambridge: Cambridge University Press. 
Guy, K. and J. Stroyan (1998) Digital Media in Finland: Evaluation Report, Technology Programme Report 12/98. Helsinki: TEKES (Finnish Funding Agency for Technology and Innovation).

Jauert, P. (2003) 'Policy Development in Danish Radio Broadcasting 1980-2002: Layers, Scenarios and the Public Service Remit', in G.F. Lowe and T. Hujanen (eds) Broadcasting and Convergence: New Articulations of the Public Service Remit. Göteborg: Nordicom.

Lax, S. (2007) 'Digital Radio and the Diminution of the Public Sphere', in R. Butsch (ed.) Media and Public Spheres. Basingstoke: Palgrave.

MINTC (1995) Yleisradiotoiminnan strategiaselvitys: Radio ja televisio 2010 [A Strategy Report on Broadcasting: Radio and Television 2010]. Helsinki: Ministry of Transport and Communications.

MINTC (2003) A Fourth Digital Broadcast Network: Creating a Market for Mobile Media Services in Finland. Helsinki: Ministry of Transport and Communications.

MINTC (2004) Radiotoiminta 2007: Työryhmän ehdotukset [Radio Broadcasting in 2007: Proposals of the Working Group]. Helsinki: Ministry of Transport and Communications.

Ofcom (2004) Radio - Preparing for the Future. Phase 1: Developing a New Framework. London: Ofcom.

OX Consultants (2004) Final Report: Review of Licensing of Radio Services in Ireland. A Study for the Department of Communication, Marine and Natural Resources. Dublin: DCMNR.

RAB (2006) Commercial Radio Revenues, URL (consulted August 2006): www.rab.co.uk

Radio Authority (2001) Local Digital Radio Multiplex Service Licences: Notes of Guidance for Applicants. London: Radio Authority.

Rajar (2006) Quarterly Summary of Radio Listening. Survey Period Ending Dec. 2005, URL (consulted August 2006): www.rajar.co.uk

RTÉ (2005) Digital Television and Radio Services in Ireland: An Introduction. Dublin: RTÉ.

Smith, C. (2005) Digital Radio Switchover. London: Digital Radio Development Bureau.

World DAB (2005) 'New Wave of DAB Legislation and Developments Worldwide', World DAB Forum press release, 14 April.

YLE (2004) Digitaaliradio: Palvelut [Digital Radio: The Services]. URL (consulted June 2005): www.yle.fi/digiradio/palvelut.htm

Stephen Lax is a lecturer at the Institute of Communications Studies, University of Leeds, UK. His research interests are in the social role of communications technologies. He is a member of the Digital Radio Cultures in Europe research group and he is on the steering group of the UK Radio Studies Network. Address: Institute of Communications Studies, University of Leeds, Leeds LS2 9JT, UK. [email: s.e.lax@leeds.ac.uk]

Marko Ala-Fossi is Senior Lecturer in Radio at the Department of Journalism and Mass Communication, University of Tampere, Finland. His research interests include different forms of local, commercial and digital radio content and production cultures, and political economy and social shaping of the new 
media delivery technologies. Address: Department of Journalism and Mass Communication, University of Tampere, 33014 University of Tampere, Finland. [email: marko.ala-fossi@uta.fi]

Per Jauert is Associate Professor at the Department of Information and Media Studies, University of Aarhus, Denmark. Address: Department of Information and Media Studies, University of Aarhus, Denmark, Helsingforsgade 14, DK8200 Aarhus N. [email: pjauert@imv.au.dk]

Helen Shaw is a $\mathrm{PhD}$ student at Dublin City University's School of Communications. She has worked in broadcast media for over 20 years and previously managed radio services for Irish public broadcasting, RTÉ. She now runs her own production company, Athena Media. She is the author of the Irish Media Directory and Guide and a guest lecturer at several universities and colleges in Ireland. Address: School of Communications, Dublin City University, Glasnevin, Dublin 11, Ireland. [email: helen@athenamedia.ie] 